\title{
Tolerability of the SQ-Standardised Grass Sublingual Immunotherapy Tablet in Adult Patients during Routine Administration - A Non- Interventional Observational Study
}

\author{
Hans-Georg Vitzthum ${ }^{1}$, Hendrik Wolf ${ }^{2 *}$, Jörg Schnitker ${ }^{3}$ and Eike Wüstenberg ${ }^{2,4}$ \\ ${ }^{1}$ ENT Physician, D-39104 Magdeburg, Germany \\ ${ }^{2}$ ALK-Abello Arzneimittel GmbH, Clinical Development, D-22763 Hamburg, Germany \\ ${ }^{3}$ Institut fur angewandte Statistik Dr. Jörg Schnitker GmbH, D-33602 Bielefeld, Germany \\ ${ }^{4}$ Universitatsklinikum Carl Gustav Carus, Clinic for Otolaryngology, Dresden, Germany
}

\begin{abstract}
Objective: The SQ-standardised grass sublingual immunotherapy (SLIT) tablet, GRAZAX ${ }^{\circledR}$ (ALK, Denmark) has been shown to be efficacious and well tolerated in a large number of clinical trials performed in Europe and USA. The aim of this study was to investigate the administration of the SQ grass SLIT-tablet in a real life setting.

Methods: This study was non-interventional, open-label, observational including 1,109 patients from 434 clinics in Germany treated between November 2006 and February 2009 with the SQ grass SLIT-tablet. Patients were followed at visits every 3 months for 9-12 months after start of therapy. Assessments included tolerability, compliance, patient satisfaction and treatment effect. Adverse drug reactions (ADRs) reported were coded by using the Medical Dictionary for Regulatory Activities (MedDRA).

Results: A total of $534(48.2 \%)$ patients experienced ADRs that were considered to be related to treatment in $299(27.0 \%)$ patients. Treatment was discontinued in $98(8.8 \%)$ patients due to ADRs. ADRs were experienced by $460(41.5 \%)$ patients after first administration and classified in $440(39.7 \%)$ patients as mild tolerable reactions at the application site needing no further treatment and in $20(1.8 \%)$ patients as intolerable reactions and reactions that needed treatment by medication all of which are specified in the summary of product characteristics for GRAZAX ${ }^{\circledR}$. Most frequently reported ADRs were paraesthesia oral, oedema mouth, oral pruritus, oral discomfort, swollen tongue and throat irritation. Serious ADRs related to treatment were reported by three patients, all patients fully recovered. Compliance $(70.9 \%)$ and patient satisfaction with the treatment effect $(92.6 \%)$ were high. Subjective well-being was improved in $74.7 \%$ of patients and symptoms and medication use were reduced versus previous seasons without SQ grass SLIT-tablet.
\end{abstract}

Conclusions: Our results confirm that the SQ grass SLIT-tablet is well tolerated during routine administration. Compliance, patient satisfaction, and treatment effect were found to be high

Keywords: Allergic rhino-conjunctivitis; GRAZAX; Grass pollen; Sublingual immunotherapy; Tolerability

Abbreviations: AIT: Allergy Immunotherapy; AE: Adverse Event; ADR: Adverse Drug Reaction; FEV1: Forced Expiratory Volume in 1 second; SCIT: Subcutaneous Immunotherapy; SLIT: Sublingual Immunotherapy; SQ: Standardised Quality.

\section{Introduction}

Allergic rhino-conjunctivitis represents a global health problem affecting $10-25 \%$ of the population and the number appears to be rising $[1,2]$. The condition is one of the main reasons for visits to primary care clinics and although usually not regarded as a severe disease it may significantly limit the quality of life of the patient as well as affecting school learning performance and work productivity [1]. Today, the treatment of allergic diseases is based on allergen avoidance, pharmacotherapy for symptom relief, and Allergy Immunotherapy (AIT). Subcutaneous allergen injections have been the main approach for the administration of immunotherapy, however, this has subsequently been extended to sublingual administration, which offers several advantages compared with the subcutaneous route, including a better safety profile, and increased convenience and compliance [3-5].

The SQ-standardised sublingual grass allergy immunotherapy tablet (SQ grass SLIT- tablet), GRAZAX ${ }^{\circledR}$ (Phleum pratense 75,000 SQ-T/2,800 BAU, ALK-Abelló, Hørsholm, Denmark), developed for sublingual application in patients with grass pollen induced rhino- conjunctivitis was launched in November 2006 in Germany and has since gained marketing authorization in most European countries through a mutual recognition procedure. The clinical efficacy and favourable tolerability profile of the SQ-grass SLIT-tablet has been reported in a large number of randomised, controlled trials in adults and children [6-18]. The most common AEs associated with the SQgrass SLIT-tablet have been mild to moderate local reactions in the mouth or throat (e.g. oral pruritus) occurring most frequently after first administration and during the initial treatment phase [6-18]. Therapy with the SQ grass SLIT-tablet is recommended to be continued for a period of 3 years. Safety and tolerability in real-life have been investigated in a phase IV clinical trial for three consecutive grass pollen

*Corresponding author: Hendrik Wolf, ALK-Abelló Arzneimittel GmbH Griegstrasse 75, Haus 25, D-22763 Hamburg, Germany, Tel: 4940703845342 Fax: 49407038455530; E-mail: hendrik.wolf@alk.net

Received October 10, 2014; Accepted November 28, 2014; Published December 05, 2014

Citation: Vitzthum HG, Wolf H, Schnitker J, Wüstenberg E (2014) Tolerability of the SQ-Standardised Grass Sublingual Immunotherapy Tablet in Adult Patients during Routine Administration-A Non-Interventional Observational Study. J Allergy Ther 5: 198. doi:10.4172/2155-6121.1000198

Copyright: (c) 2014 Vitzthum HG, et al. This is an open-access article distributed under the terms of the Creative Commons Attribution License, which permits unrestricted use, distribution, and reproduction in any medium, provided the original author and source are credited. 
seasons in 628 patients in France [19], in an observational study in 155 patients in Spain for the first 30 days of treatment [20] and in a noninterventional observational study in 797 children and adolescents and 964 adult patients for the first 9-12 months of treatment in Germany [21].

The SQ grass SLIT-tablet has been developed according to one of the largest clinical development programs for a product of allergy immunotherapy. More than 6,300 patients have been involved in the controlled clinical trials performed in Europe and USA, which collectively have demonstrated clinical efficacy and a favourable safety profile of the SQ grass SLIT-tablet in adults and children [6-18].

AIT has been attributed with altering the natural course of the disease, thereby entailing sustained reductions in symptoms and disease modifying effect [22,23]. However, importantly, sustained clinical effect in the first and second grass pollen season without therapy after 3 years of continuous treatment has only been documented with GRAZAX $^{\circledR}$, resulting in GRAZAX ${ }^{\circledR}$ being the only AIT with a disease modification indication $[15,16]$. The safety data obtained for the SQ grass SLIT-tablet during the clinical development program have shown that the most frequently reported adverse events (AEs) were mild to moderate, transient application-site related events with the most common reactions being oral pruritus, mouth oedema, ear pruritus, and throat irritation.

The aim of the present non-interventional, observational and open-label study was to investigate the SQ grass SLIT-tablet in the real life setting in Germany in which the tablet has been routinely prescribed by physicians since launch in November 2006. In particular, it was investigated whether the favourable safety profile obtained in the clinical development program could be confirmed during routine use. In addition, compliance and patient satisfaction with treatment and treatment effect of the SQ grass SLIT-tablet were assessed.

\section{Methods}

\section{Study design}

This study was multi-centre, open, uncontrolled, and observational according to non-interventional post-authorization surveillance studies mentioned in the German drug law for recording of data concerning tolerability and routine application of drugs after marketing authorization [22]. The costs of treatment were covered by the German health insurance system.

Centres were distributed all over Germany and were asked to record data on 2 to 3 patients in a consecutive order dependent on the patient's willingness to participate in the study in order to avoid a selection bias. Treatment with the oral dispersible SQ-standardised grass SLIT-tablet, GRAZAX ${ }^{\circledR}$ (Phleum pratense 75,000 SQ-T/2,800 BAU, approximately $15 \mu \mathrm{g}$ major allergen Phleum p 5) was initiated after the grass pollen seasons in 2006 and 2007 (the season is usually between May and August in Germany). The first administration of the SQ grass SLIT-tablet was performed at the clinic (visit 1) where patients stayed for at least 30 minutes after the first dosing, in order to enable patient and clinician to discuss any side effects. Subsequently, the SLIT-tablet was taken by the patient at home. After visit 1, patients were followed at control visits every 3 months when they attended the clinic to get the prescription of the SQ grass SLIT-tablet renewed. Each patient was followed for about 9 to 12 months (4-5 visits) until the end of the first grass pollen season (seasons 2007 and 2008) after start of therapy. The study diagram is shown in Figure 1.

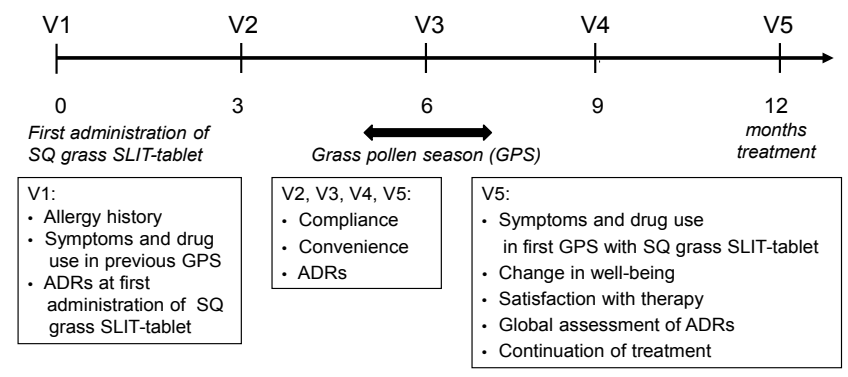

Figure 1: Study diagram. Time schedule and major observations of the study. The SQ grass SLIT-tablet was first administered in the clinic at visit 1 (V1). Patients visited the allergist's office subsequently about every 3 months at visit 2 (V2), visit 3 (V3), visit 4 (V4) and visit 5 (V5) for an observation period of up to 12 months. The final visit was performed after the grass pollen season (GPS). $A D R=$ Adverse drug reaction, SLIT=Sublingual immunotherapy.

\begin{tabular}{|c|c|}
\hline $\begin{array}{l}\text { SQ-grass SLIT-tablet first administered } \\
\text { Discontinued } \\
\text { - Intolerable ADR } \\
\text { - Not returned } \\
\text { Continued } \\
\text { No follow-up visit documented } \\
\text { - Documentation stopped (treatment continued) } \\
\text { - Not returned } \\
\text { Prematurely terminated }\end{array}$ & $\begin{array}{l}n=1,109 \\
n=13 \\
n=7 \\
n=6 \\
n=1,096(98.8 \%) \\
n=81 \\
n=1 \\
n=52 \\
n=28\end{array}$ \\
\hline $\begin{array}{l}\text { At least } 1 \text { follow-up visit } \\
\text { Last follow-up visit before grass pollen season } \\
\text { - Documentation stopped (treatment continued) } \\
\text { - Not returned } \\
\text { - Prematurely terminated } \\
\text { Last follow-up visit during grass pollen season } \\
\text { - Documentation stopped (treatment continued) } \\
\text { - Not returned } \\
\text { - Prematurely terminated }\end{array}$ & $\begin{array}{l}n=1,015(\mathbf{9 1 . 5 \% )} \\
\mathrm{n}=80 \\
\mathrm{n}=6 \\
\mathrm{n}=26 \\
\mathrm{n}=48 \\
\mathrm{n}=116 \\
\mathrm{n}=41 \\
\mathrm{n}=48 \\
\mathrm{n}=27\end{array}$ \\
\hline $\begin{array}{l}\text { Patients with at least } 1 \text { post-seasonal follow-up visit } \\
\text { Discontinued after grass pollen season } \\
\text { - Not returned } \\
\text { - Prematurely terminated }\end{array}$ & $\begin{array}{l}n=819(73.9 \%) \\
n=74 \\
n=26 \\
n=48\end{array}$ \\
\hline Continued after last post-seasonal follow-up visit & $n=745(67.2 \%)$ \\
\hline
\end{tabular}

Figure 2: Flow of patients through the study.

\section{Patients}

In the study 1,109 patients were included from 434 clinics distributed over Germany.

The 'Flow of patients through the study' is shown in Figure 2. Patients with a diagnosis of grass pollen-induced rhinitis and/or conjunctivitis (according to symptoms, skin prick test or RAST) with or without asthma with clinically relevant symptoms who had no contraindications to a prescription according to the 'Summary of Product Characteristics' of GRAZAX ${ }^{\circledR}$ were eligible to be documented in this study after giving their oral consent. Patients applied symptomatic medication during the grass pollen season as needed.

Indications according to the summary of product characteristics are: Disease-modifying treatment of grass pollen induced rhinitis and conjunctivitis in adults and children (5 years or older), with clinically 
Citation: Vitzthum HG, Wolf H, Schnitker J, Wüstenberg E (2014) Tolerability of the SQ-Standardised Grass Sublingual Immunotherapy Tablet in Adult Patients during Routine Administration-A Non-Interventional Observational Study. J Allergy Ther 5: 198. doi:10.4172/2155-6121.1000198

Page 3 of 7

relevant symptoms and diagnosed with a positive skin prick test and/or specific IgE test to grass pollen. Contraindications are: Hypersensitivity to any of the excipients, malignancy or systemic diseases affecting the immune system e.g. autoimmune diseases, immune complex diseases or immune deficiency diseases, inflammatory conditions in the oral cavity with severe symptoms such as oral lichen planus with ulcerations or severe oral mycosis. Patients with uncontrolled or severe asthma (in adults: $\mathrm{FEV}_{1}<70 \%$ of predicted value after adequate pharmacologic treatment, in children: $\mathrm{FEV}_{1}<80 \%$ of predicted value after adequate pharmacologic treatment) should not be treated with GRAZAX immunotherapy.

\section{Assessments}

In the present study, tolerability, compliance, satisfaction with treatment, and treatment effect with the SQ grass SLIT-tablet were assessed. Evaluation of tolerability was based on the physicians' assessment of adverse drug reactions (ADRs) after the first administration of the SLIT-tablet and at the patients' description at all follow-up visits during the entire study period. In addition, an overall assessment of tolerability (very good/good/moderate/poor) was performed by patient and physician at the final visit of the study. ADRs following the first application of the SQ grass SLIT-tablet was classified as either tolerable or intolerable reactions. At the subsequent follow-up visits, ADRs were recorded as reported by the patients. Tolerable reactions were defined as mild reactions at the application site that are specified in the summary of product characteristics and these were not specified further in the CRF. Serious ADRs were further documented on a separate report form, and if applicable according to legal pharmacovigilance procedures, they were notified to the authorities. Compliance was assessed at the follow-up visits by asking the patient whether the tablet had been taken regularly during the last prescription interval (yes/no). If the answer was "no", the patient was asked how often the therapy had been interrupted (occasionally/ frequently). In addition, the patient was asked for the reason for the interruption (forgotten/ADRs/other). A frequent interruption was regarded as a criterion of non-compliance. Further criteria of noncompliance were: "patient lost to follow-up", "termination of treatment for other compliance reasons", and "missing control visits". A patient was considered as non-compliant if at least one criterion of noncompliance was fulfilled.

Satisfaction with treatment was assessed at the final visit by 2 variables; Easiness and convenience of taking the SQ grass SLITtablet (easy and convenient/so-so/difficult and inconvenient) as well as satisfaction with the efficacy of treatment (very satisfied/satisfied/ dissatisfied/very dissatisfied). These variables were analysed separately as well as combined thereby giving the overall satisfaction rate. Overall satisfaction with treatment applied if the patient found that it was both "easy" and "convenient" to take the SQ grass SLIT-tablet and if the patient was "satisfied" or "very satisfied" with the efficacy of the treatment.

Treatment effect of the SQ grass SLIT-tablet was investigated by asking the patients at in-season visits to assess their subjective wellbeing compared to the previous season without allergy immunotherapy (much improved/improved/no change/worse/much worse). In addition, the severity of symptoms (no/mild/moderate/severe) at nose, eyes, lung, and skin and the use of symptomatic medication (no/topical

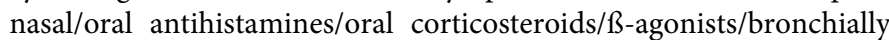
applied corticosteroids) in the first season with the SQ grass SLITtablet was compared with the severity of symptoms and medication use in the season before start of therapy as determined retrospectively during visit 1 .

\section{Statistics}

Data analysis was performed solely by descriptive statistics using minimum, maximum, median, mean, range and standard deviation for continuous data as well as frequency distributions for ordinal data. No imputation was performed in case of missing data, but all available data was used to its full extent. The principal statistical software used was SAS $^{\circledR}$, versions 8.2.0 and 9.1.3.

ADRs were displayed for patients and on the level of events including multiple occurrences by patient. ADRs were coded according to the current version of the Medical Dictionary for Regulatory Activities (MedDRA).The sample size was planned to be at least 900 in order to detect ADRs of low incidence (0.5\%) with high probability (99\%) at least once. We, therefore, aimed to include at least 400 physicians in the study who should record data of 2-3 patients on average.

\section{Results}

\section{Patients}

The study was initiated in November 2006 and the last patient completed the study in February 2009. Patient characteristics are displayed in Table 1 .

First administration of the SQ grass SLIT-tablet in the clinic was performed in 1,109 patients in 434 clinics.

The flow of patients through the study is shown in Figure 2. The SQ grass SLIT-tablet was prescribed for home treatment in 1,096 patients.

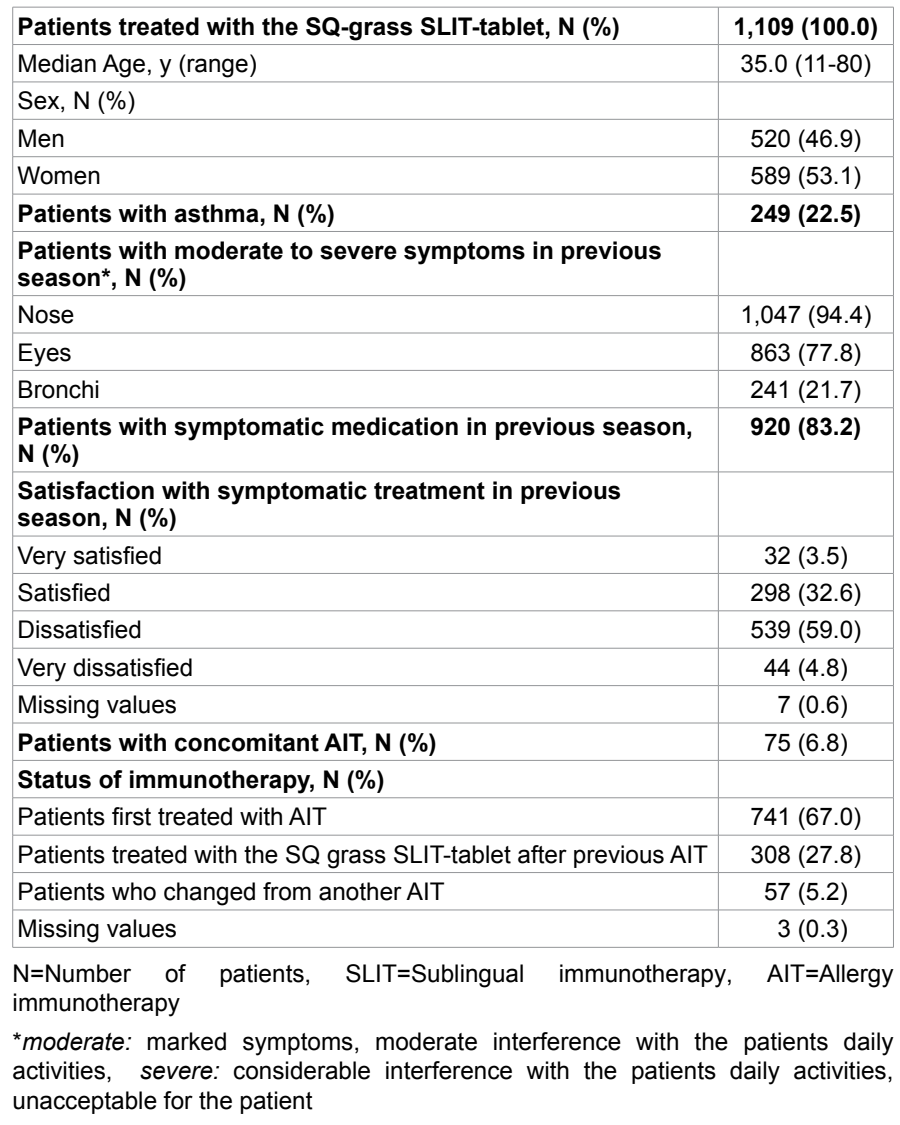

Table 1: Patient characteristics. 


\begin{tabular}{|l|c|c|}
\hline Patients & N & \% \\
\hline All patients treated (at least first administration) & 1,109 & 100.0 \\
\hline No ADRs & 575 & 51.8 \\
\hline ADRs & 534 & 48.2 \\
\hline ADRs at least "possibly" related & 299 & 27.0 \\
\hline Serious ADRs & 4 & 0.4 \\
\hline Discontinued due to ADRs & 98 & 8.8 \\
\hline Medically treated due to ADRs & 67 & 6.0 \\
\hline First administration of the SQ-grass SLIT-tablet in the clinic & & \\
\hline No ADRs & 649 & 58.5 \\
\hline Tolerable ADRs & 440 & 39.7 \\
\hline Intolerable ADRs & 20 & 1.8 \\
\hline ADRs during home treatment & 318 & 28.7 \\
\hline
\end{tabular}

$\mathrm{N}$ : Number of patients

ADR: Adverse drug reactions

SLIT:Sublingual immunotherapy

Table 2: Patients with adverse drug reactions.

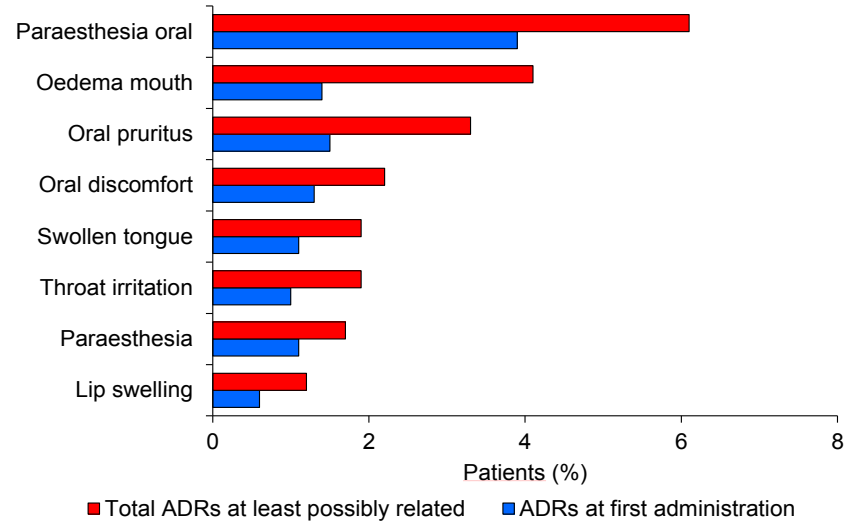

Figure 3: Frequency of treatment-related adverse drug reactions (ADRs) Frequency of ADRs at least possibly related with the SQ grass SLIT-table (observed in $>1 \%$ of patients) as total ADRs at least possible related and ADRs at first administration (MedDRA preferred terms).

A total of 1,015 patients had at least one follow-up visit and 819 patients had at least one post-seasonal follow-up visit. A total of 745 patients continued treatment at the end of the observation period of the study.

\section{Tolerability}

ADRs occurring after the first administration of the SLIT-tablet were recorded as either tolerable or intolerable. At the subsequent follow-up visits during the course of the study, ADRs were recorded as reported by the patients (Table 2). Overall, ADRs occurred in 534 (48.2\%) of the total number of patients and in 299 patients $(27.0 \%)$ the ADRs were considered at least possibly related to the treatment with the SQ grass SLIT-tablet. The treatment was discontinued in $98(8.8 \%)$ of the patients due to ADRs and in 67 (6.0\%) of the patients medication (predominantly antihistamines and/or oral corticosteroids) was given to treat the reactions.

The first administration of the SQ grass SLIT-tablet was tolerated without any ADRs by 649 (58.5\%) patients whereas 460 (41.5\%) patients experienced ADRs; 440 patients $(39.7 \%)$ had tolerable reactions and 20 patients (1.8\%) had intolerable reactions. The most frequently reported reactions after first administration were oral paraesthesia, oral pruritus, mouth oedema, oral discomfort, swollen tongue, and paraesthesia and throat irritation (Figure 3). Out of the 20 patients with intolerable reactions after first tablet administration, the SQ grass SLIT-tablet was not prescribed in 7 patients, prescribed but discontinued shortly after prescription in 8 patients, and prescribed and then continued regularly over the period of the study in 5 patients.

During home treatment, ADRs were reported by $318(28.7 \%)$ patients who experienced 1-15 events each (600 reactions in total). The most frequent treatment related ADRs ( $>1 \%$ of patients) reported for patients during home treatment were similar to the reactions documented after first administration (Figure 3). Serious ADRs occurred in 4 patients, 3 of which were considered related to the treatment. In 2 of these patients, who were hospitalized due to dyspnoea and throat swelling, and due to urticaria and Quincke's oedema, respectively, the reactions were considered as related to the treatment. Both patients fully recovered. The third patient took the first tablet by himself outside the clinic without observation and reported an anaphylactic reaction with symptoms of throat tightness, dyspnoea, difficulty swallowing (dysphagia), palpitations, dizziness and decreased blood pressure (blood pressure not measured) which started 2 minutes after administration. The patient applied adrenaline from an autoinjector (Anapen $0.3 \mathrm{mg}$ ) 10 minutes after the reaction started and 2 times $5 \mathrm{mg}$ levocetirizine 30 and 90 minutes after the reaction started. Symptoms abated and patient fully recovered after 2 hours. Due to the application of adrenaline the case was classified as medically important. In the fourth patient who was hospitalised due to unconsciousness, disorientation and fever the reaction was considered unlikely related to the treatment.

Comparing the incidence of ADRs for patients treated with the SQ grass SLIT-tablet only $(\mathrm{N}=1,034)$ and for patients with the SQ grass SLIT-tablet and a concomitant AIT $(\mathrm{N}=75), 28(37.3 \%)$ patients with concomitant AIT had tolerable ADRs and $2(2.7 \%)$ had intolerable ADRs leading to supervision or discontinuation of further administration of the SLIT-tablet; $412(39.8 \%)$ patients treated with the SQ grass SLIT-tablet only had tolerable and 18 (1.7\%) had intolerable ADRs. No statistically significant difference in the incidence of ADRs between the two groups was detected ( $\mathrm{p}=0.7891, \chi^{2}$ test). During the course of treatment with the SQ grass SLIT-tablet, concomitant AIT was initiated in 33 patients. No differences in the incidence of ADRs have been detected regardless whether the concomitant AIT was ongoing at first administration of the SQ grass SLIT-tablet or initiated during the course of treatment with the SLIT-tablet.

In the overall assessment of tolerability performed at the last visit post-season, tolerability was assessed as "good" or "very good" by $87.2 \%$ of the patients and by $89.5 \%$ of the physicians.

\section{Compliance}

The SQ grass SLIT-tablet was taken regularly every day by 732 (72.1\%) of the 1,015 patients who had at least one follow-up visit (Table 3). Out of all patients treated $(\mathrm{N}=1,109), 323$ patients $(29.1 \%)$ met at least one criterion of non-compliance including 160 patients with unknown compliance (i.e. who missed the control visits). The frequency of patients who met the different criteria of non-compliance is displayed in Table 3. The overall compliance rate was $70.9 \%$ for all patients treated, $74.0 \%$ for patients with at least one follow-up visit, and $81.4 \%$ for patients with at least one post-seasonal visit.

\section{Patient satisfaction}

Out of the 819 patients who had at least one post-seasonal visit, 723 (89.6\%, 12 missing values) patients assessed taking the SQ grass SLIT-tablet to be easy and convenient (Table 3). A total of 737 (92.6\%, 23 missing values) patients were "very satisfied" or "satisfied" with the 


\begin{tabular}{|l|c|c|}
\hline Patients & $\mathbf{N}$ & $\%$ \\
\hline Patients with evaluable compliance data & $\mathbf{1 , 0 1 5}$ & $\mathbf{1 0 0 . 0}$ \\
\hline SQ grass SLIT-tablet daily administered & & \\
\hline \multicolumn{1}{|c|}{ Regularly } & 732 & 72.1 \\
\hline \multicolumn{1}{|c|}{ Irregularly } & 283 & 27.9 \\
\hline Patients lost-to-follow-up & 158 & 14.2 \\
\hline Premature termination due to lack of compliance & 14 & 1.3 \\
\hline Missing control visits & 160 & 14.4 \\
\hline Patients with frequent irregular administration & 40 & 3.6 \\
\hline Assessment of easiness and convenience of taking the & $\mathbf{8 0 7}$ & $\mathbf{1 0 0 . 0}$ \\
\hline SQ grass SLIT-tablet & & \\
\hline 'Easy and convenient' & 723 & 89.6 \\
\hline 'So-so' & 81 & 10.0 \\
\hline 'Difficult and inconvenient' & 3 & 0.4 \\
\hline Assessment of satisfaction with efficacy of treatment & $\mathbf{7 9 6}$ & $\mathbf{1 0 0 . 0}$ \\
\hline Very satisfied & 368 & 46.2 \\
\hline Satisfied & 369 & 46.4 \\
\hline Dissatisfied & 56 & 7.0 \\
\hline Very dissatisfied & 3 & 0.4 \\
\hline
\end{tabular}

$\mathrm{N}$ : Number of patients

SLIT: Sublingual immunotherapy

Table 3: Compliance and patient satisfaction.

efficacy of treatment (Table 3). The overall satisfaction rate was $81.9 \%$.

\section{Subjective assessment of treatment effect}

The subjective well-being during the first season with the SQ grass SLIT-tablet as compared to the previous season was assessed as "much improved" or "improved" by $74.7 \%$ of the patients with documentation available for this assessment ( $\mathrm{N}=677 ; 23.5 \%$ "no change", $1.5 \%$ "worse", $0.3 \%$ "much worse"). For nose, eye, bronchial, and skin symptoms, 84.9\% ( $\mathrm{N}=798$ patients with assessments), 79.2\% ( $\mathrm{N}=795), 73.3 \%$ $(\mathrm{N}=768)$, and $74.8 \%(\mathrm{~N}=750)$ of the affected patients, respectively, assessed their condition as "free of symptoms" or "improved" in the first season with treatment compared with the season before start of therapy. Patients who had used symptomatic medication in the season before start of immunotherapy did not use symptomatic medication in the first season with the SQ grass SLIT-tablet in 246/456 (53.9\%) patients for nasal topical medication, 329/541 (60.8\%) for oral antihistamines, 50/55 (90.9\%) for oral corticosteroids, 49/80 (61.3\%) for bronchial $\beta$-agonists, and 24/55 (43.6\%) for bronchial corticosteroids.

\section{Discussion}

In this large non-interventional, observational study, data for tolerability, compliance, patient satisfaction and treatment effect were recorded for more than 1,000 patients who had been treated with the then newly available SQ-standardised grass SLIT-tablet, GRAZAX ${ }^{\circledR}$, after launch of the product in Germany in November 2006.

Overall, it was confirmed that the safety profile obtained for the SQ grass SLIT-tablet during the clinical development program also applies for the real life setting during routine application.

According to the actual German guidelines, AIT is indicated in patients sensitized to the treated allergen, patients who have bothersome symptoms (rhino-conjunctivitis, asthma) and if the allergen cannot be avoided [24]. This does not necessarily include that the patient has taken symptomatic drugs in the previous grass pollen season to treat his symptoms. The observation that $94.4 \%$ of patients in our study assessed to have moderate to severe nasal symptoms and less patients $(83.2 \%)$ specified to have taken symptomatic medication in the previous grass pollen season before treatment with the SQ grass SLITtablet reflects that some patients did not take symptomatic medication despite of considerable severity of symptoms. Similar observations have been made in other non-interventional studies [21].

In two large placebo-controlled phase III trials previously performed in Europe with the SQ grass SLIT-tablet including 634 adults (316 actively treated and 318 with placebo) [11] and 253 children (126 actively treated and 127 with placebo) [13], respectively, comparable frequencies of adverse events $(\mathrm{AE})$ were reported. In the study with adults, 265 out of 316 actively treated patients had at least $1 \mathrm{AE}(84 \%)$ and $74(23 \%)$ patients had AEs possibly related to active treatment. Most frequent reactions were oral pruritus, mouth oedema, ear pruritus, and throat irritation [11]. In the study with children, 109 out of 126 actively treated patients (87\%) had AEs; 27 (21\%) had AEs possibly related to active treatment and 53 (42\%) had AEs probable related to active treatment [13]. Most frequent reactions in children were oral pruritus, throat irritation, swollen lip and cough. Accordingly, in two US-trials with 345 children in which $n=149$ subjects received the SQ grass SLIT-tablet and $n=158$ placebo, [17] and with 439 adults in which $n=213$ subjects received the SQ grass SLIT-tablet and $n=225$ placebo [18] similar results for safety and tolerability were obtained.

In the present study, ADRs were reported less frequently compared with the overall $\mathrm{AE}$ rates in two controlled phase III trials mentioned above $[11,13] ; 41.5 \%$ of the patients reported ADRs after the first administration $(39.7 \%$ of the patients reported tolerable ADRs and $1.8 \%$ reported intolerable ADRs); $28.7 \%$ of the patients reported ADRs during home administration; overall reactions to the SQ grass SLIT-tablet were reported in $48.2 \%$ of the patients including patients who had tolerable reactions after first administration and for $27.0 \%$ of all patients treated reactions assessed as at least possibly related to treatment were observed. This lower incidence of ADRs compared with the incidence in the controlled clinical trials is to be expected for a study with an open observational design and routine administration of the treatment after marketing authorization because in controlled clinical trials adverse events are more intensively documented and monitored. In real-life studies often higher numbers of patients are included representing patients routinely treated that are not highly selected as in randomized controlled clinical trials.

In contrast to subcutaneous immunotherapy (SCIT), SLIT is considered to be more safe and is, therefore, suited to be administered at home outside of the medical setting [4,5]. SCIT is considered safe when performed in a specialist clinic by trained staff, with immediate presence of a doctor experienced in immunotherapy and access to resuscitative measures, but carries a small risk of significant adverse effects [4]. SLIT appears to be better tolerated than SCIT because the majority of SLIT adverse events are local reactions (e.g. oromucosal pruritus) that occur during the beginning of treatment and resolve within a few days or weeks without any medical intervention (e.g. dose adjustment, medication) [5]. Many clinical trials have shown that SLIT (drops or tablets) is well tolerated in adults and children. Nonethe-less $40-85 \%$ of patients experience local side effects, such as mild itching and mild swelling of the lips [4]. The tolerability data from our study are in agreement with these statements from a recently published review article on allergy immunotherapy and the current update of the Position paper on SLIT of the World Allergy Organization [4,5]. The majority of the ADRs observed were local reactions at the application site in the mouth (oral pruritus, mouth oedema, swollen tongue, throat irritation), systemic reactions like e.g. respiratory symptoms that are more frequently observed with SCIT were rarely observed in our study 
Citation: Vitzthum HG, Wolf H, Schnitker J, Wüstenberg E (2014) Tolerability of the SQ-Standardised Grass Sublingual Immunotherapy Tablet in Adult Patients during Routine Administration-A Non-Interventional Observational Study. J Allergy Ther 5: 198. doi:10.4172/2155-6121.1000198

Page 6 of 7

with the SQ grass SLIT-tablet ( $\leq 1 \%$ of patients), ADRs were treated by medication in $6.8 \%$ of patients and treatment was discontinued due to ADRs in $8.8 \%$. Severe ADRs classified as serious were observed in 4 patients $(0.4 \%)$ and were considered related to treatment in 3 patients $(2$ patients hospitalized: one patient due to dyspnoea and throat swelling and one patient due to Urticaria and Quincke's oedema, one patient who had initiated treatment without medical supervision reported throat tightness, dyspnoea and decreased blood pressure and treated himself by adrenaline from an auto-injector and antihistamines). All patients were fully recovered. Altogether, the tolerability profile observed was in agreement with the phase III trials in adults and children [10-18] and observational studies of real-life applications [1921]. Accordingly, the reported ADRs were known and expected and are already mentioned in the current summary of product characteristics for GRAZAX ${ }^{\circledR}$.

Overall tolerability was assessed at the end of the study as "good" or "very good" by $87.2 \%$ of the patients and by $89.5 \%$ of the physicians further supporting the favourable safety profile of the SQ grass SLITtablet also in the real life setting. Compliance, patient satisfaction, and efficacy of the SQ grass SLIT-tablet were also assessed in the present study and all these measures were favourably rated by the patients.

A large proportion of the patients (72.1\%) applied the SQ grass SLIT-tablet on a regular basis and accordingly the overall compliance rate for the daily sublingual administration of the tablet was high with about $70 \%$ of patients without any compliance problems.

Regarding patient satisfaction, the majority of the patients (89.6\%) with at least one visit post-season, assessed taking the SQ grass SLITtablet to be easy and convenient. Patient satisfaction with the efficacy of treatment was high with most of the patients (92.6\%) being "very satisfied" or "satisfied". The overall treatment satisfaction rate was $81.9 \%$.

The subjective well-being of the patients in the first grass pollen season after start of treatment with the SQ grass SLIT-tablet was recorded in our study for about $75 \%$ of the patients as "much improved" or "improved". Moreover, the majority of patients assessed their nose (84.9\%), eye (79.2\%), bronchial (73.3\%), and skin (74.8\%) symptoms during the first season treated with the SQ grass SLIT-tablet as "free of symptoms" or "improved" as compared with the status before treatment. Likewise, several of the patients who had used symptomatic medication in the previous season before start of immunotherapy did not use medication in the first season with the SQ grass SLIT-tablet. These results are in accordance with the rate of $82 \%$ of the patients improved for the global evaluation of the treatment effect in the actively treated group from the large European phase III clinical trial in adults [11] and they indicate that treatment with the SQ grass SLIT-tablet is highly effective also in the real life setting.

Limitations of our study are those of a prospective, open-label, uncontrolled observational study. In order to minimize a potential investigator bias a large number of sites distributed all over Germany were involved. For reduction of a potential selection bias physicians were asked to include patients in a consecutive order according to the consent of the patients to be included in the study.

In conclusion, the SQ grass SLIT-tablet was well tolerated during routine use in our study in Germany. The safety profile was in good accordance with the safety and tolerability profile known from large controlled clinical trials conducted before launch in adults and children. Compliance with treatment was high and the patients were highly satisfied with the effect of treatment and assessed taking the SQ grass SLIT-tablet to be easy and convenient.

\section{Competing Interests}

HG Vitzthum received remuneration from ALK for the documentation of patient data from his clinic for this study. J Schnitker was funded by ALK as Clinical Research Organization in the study. $\mathrm{H}$ Wolf and E Wüstenberg are employees of ALK.

\section{Authors Contributions}

HV was study investigator. HW contributed to conception and design and interpretation of the data and has been involved in drafting the manuscript. JS contributed to conception and design and analysis of data. EW contributed to conception and design and interpretation of the data. All authors read and approved the final manuscript.

\section{Acknowledgement}

We would like to thank all physicians who participated in the GRAZAX START study and Sidse Ørnbjerg Würtz who helped in preparing the manuscript.

\section{References}

1. Bousquet J, Van Cauwenberge P, Khaltaev N, Aria Workshop Group, World Health Organization. (2001) Allergic rhinitis and its impact on asthma. J Allergy Clin Immunol 108:S147-S334.

2. Linneberg A, Gislum M, Johansen N, Husemoen LL, Jørgensen T (2007) Temporal trends of aeroallergen sensitization over twenty-five years. Clin Exp Allergy 37: 1137-1142.

3. COMMITTEE FOR MEDICINAL PRODUCTS FOR HUMAN USE (CHMP) (2008) Guideline on the clinical development on products for specific immunotherapy for the treatment of allergic diseases. EMEA

4. Cappella A, Durham SR (2012) Allergen immunotherapy for allergic respiratory diseases. Hum Vaccin Immunother 8: 1499-1512.

5. Canonica GW, Cox L, Pawankar R, Baena-Cagnani CE, Blaiss M, et al. (2014) Sublingual immunotherapy: World Allergy Organization position paper 2013 update. World Allergy Organ J 7: 6.

6. Malling HJ, Lund L, Ipsen H, Poulsen LK (2006) Safety and immunological changes during specific sublingual immunotherapy with $\mathrm{SQ}$ standardized grass allergen tablets. Journal Investig Allergol Clin Immunol 16:162-168.

7. Kleine-Tebbe J, Ribel M, Herold DA (2006) Safety of a SQ-standardised grass allergen tablet for sublingual immunotherapy: a randomized, placebo-controlled trial. Allergy 61: 181-184

8. Calderón M, Essendrop M (2006) Specific immunotherapy with high dose SO standardized grass allergen tablets was safe and well tolerated. J Investig Allergol Clin Immunol 16: 338-344.

9. Ibañez MD, Kaiser F, Knecht R, Armentia A, Schöpfer H, et al. (2007) Safety of specific sublingual immunotherapy with SQ standardized grass allergen tablets in children. Pediatr Allergy Immunol 18: 516-522.

10. Durham SR, Yang WH, Pedersen MR, Johansen N, Rak S (2006) Sublingual immunotherapy with once-daily grass allergen tablets: a randomized controlled trial in seasonal allergic rhinoconjunctivitis. J Allergy Clin Immunol 117: 802809

11. Dahl R, Kapp A, Colombo G, de Monchy JG, Rak S, et al. (2006) Efficacy and safety of sublingual immunotherapy with grass allergen tablets for seasonal allergic rhinoconjunctivitis. J Allergy Clin Immunol 118: 434-440.

12. Dahl R, Stender A, Rak S (2006) Specific immunotherapy with SQ standardized grass allergen tablets in asthmatics with rhinoconjunctivitis. Allergy 61: 185190

13. Bufe A, Eberle P, Franke-Beckmann E, Funck J, Kimmig M, et al. (2009) Safety and efficacy in children of an SQ-standardized grass allergen tablet for sublingual immunotherapy. J Allergy Clin Immunol 123: 167-173.

14. Dahl R, Kapp A, Colombo G, De Monchy JG, Rak S, et al. (2008) Sublingual grass allergen tablet immunotherapy provides sustained clinical benefit with progressive immunologic changes over 2 years. J Allergy Clin Immunol 121:512-518. 
Citation: Vitzthum HG, Wolf H, Schnitker J, Wüstenberg E (2014) Tolerability of the SQ-Standardised Grass Sublingual Immunotherapy Tablet in Adult Patients during Routine Administration-A Non-Interventional Observational Study. J Allergy Ther 5: 198. doi:10.4172/2155-6121.1000198

15. Durham SR, Emminger W, Kapp A, Colombo G, de Monchy JGR, et al. (2010) Long-term clinical efficacy in grass pollen-induced rhinoconjunctivitis after treatment with SQ-standardized grass allergy immunotherapy tablet. J Allergy Clin Immunol 125:131-138.

16. Durham SR, Emminger W, Kapp A, de Monchy JG, Rak S, et al. (2012) $S Q$-standardized sublingual grass immunotherapy: confirmation of disease modification 2 years after 3 years of treatment in a randomized trial. J Allergy Clin Immunol 129: 717-725.

17. Blaiss M, Maloney J, Nolte H, Gawchik S, Yao R, et al. (2011) Efficacy and safety of timothy grass allergy immunotherapy tablets in North American children and adolescents. J Allergy Clin Immunol 127: 64-71, 71.

18. Nelson HS, Nolte H, Creticos P, Maloney J, Wu J, et al. (2011) Efficacy and safety of timothy grass allergy immunotherapy tablet treatment in North American adults. J Allergy Clin Immunol 127: 72-80, 80.

19. Wessel F, Chartier A, Meunier JP, Magnan A (2012) Safety and tolerability of an SQ-standardized GRAss ALlergy immunotherapy tablet (GRAZAX®) in a reallife setting for three consecutive seasons - the GRAAL trial. Clin Drug Investig 32: 451-463.
20. Armentia A, Carballada F, Carretero P, de Paz S, Lobera T, et al. (2012) Postmarketing study for assessment of tolerability of a grass allergen immunotherapy tablet (GRAZAX) in patients with rhinitis or rhinoconjunctivitis. J Investig Allergol Clin Immunol 22: 485-490.

21. Gronke C, Wolf H, Schnitker J, Wüstenberg E (2013) Treatment with the SQ-Standardised Grass Allergy Immunotherapy Tablet is well Tolerated in Children, Adolescents and Adults in Real Life Application-A Non-Interventional Observational Study. J Allergy Ther 4:146. doi:10.4172/2155-6121.1000146.

22. Medicinal Products Act (The Drug law)

23. EMEA. Guideline on the clinical development on products for specific immunotherapy for the treatment of allergic diseases. 2008 Jun 1. Report No. CHMP/EWP/18504/2006.

24. Kleine-Tebbe J, Bufe A, Ebner C, Eigenmann P, Friedrich F et al. (2009) German S-2-Guideline Specific immunotherapy at IgE-mediated allergic diseases. Allergo J 18:508-537 